\title{
Essential amino acid supplementation in patients following total knee arthroplasty
}

\author{
Hans C. Dreyer, ${ }^{1}$ Lisa A. Strycker, ${ }^{2}$ Hilary A. Senesac, ${ }^{1}$ Austin D. Hocker, ${ }^{1}$ Keith Smolkowski, ${ }^{2}$ \\ Steven N. Shah, ${ }^{3}$ and Brian A. Jewett ${ }^{3}$
}

\begin{abstract}
${ }^{1}$ Department of Human Physiology, University of Oregon, Eugene, Oregon, USA. ${ }^{2}$ Oregon Research Institute, Eugene, Oregon, USA. ${ }^{3}$ Slocum Center for Orthopedics and Sports Medicine, Eugene, Oregon, USA.
\end{abstract}

Background. By the year 2030, 3.48 million older U.S. adults are projected to undergo total knee arthroplasty (TKA). Following this surgery, considerable muscle atrophy occurs, resulting in decreased strength and impaired functional mobility. Essential amino acids (EAAs) have been shown to attenuate muscle loss during periods of reduced activity and may be beneficial for TKA patients.

Methods. We used a double-blind, placebo-controlled, randomized clinical trial with 28 older adults undergoing TKA. Patients were randomized to ingest either $20 \mathrm{~g}$ of EAAs $(n=16)$ or placebo $(n=12)$ twice daily between meals for 1 week before and 2 weeks after TKA. At baseline, 2 weeks, and 6 weeks after TKA, an MRI was performed to determine mid-thigh muscle and adipose tissue volume. Muscle strength and functional mobility were also measured at these times.

Results. TKA patients receiving placebo exhibited greater quadriceps muscle atrophy, with a $-14.3 \pm 3.6 \%$ change from baseline to 2 weeks after surgery compared with $-3.4 \pm 3.1 \%$ for the EAA group $(F=5.16, P=0.036)$ and a $-18.4 \pm$ $2.3 \%$ change from baseline to 6 weeks after surgery for placebo versus $-6.2 \pm 2.2 \%$ for the EAA group $(F=14.14$, $P=0.001)$. EAAs also attenuated atrophy in the nonoperated quadriceps and in the hamstring and adductor muscles of both extremities. The EAA group performed better at 2 and 6 weeks after surgery on functional mobility tests (all $P<0.05)$. Change in quadriceps muscle atrophy was significantly associated with change in functional mobility $(F=5.78, P=0.021)$.

Conclusion. EAA treatment attenuated muscle atrophy and accelerated the return of functional mobility in older adults following TKA.

\section{Trial registration. Clinicaltrials.gov NCT00760383.}

Funding. Eunice Kennedy Shriver National Institute of Child Health and Human Development (NICHD), Office of the Director (OD), and the National Institutes of Health Office of Dietary Supplements (ODS), NIH grant K01HD057332, and the Medical Research Foundation, Oregon Health and Science University. The funders had no role in study design, data collection and analysis, decision to publish, or preparation of the manuscript. The content of this manuscript is solely the responsibility of the authors and does not necessarily represent the official views of the funders.

\section{Introduction}

By the year 2030, the demand for primary total knee arthroplasty (TKA) is projected to increase nearly 7 -fold to 3.4 million surgeries performed annually in the U.S. (1). Muscle atrophy and weakness in the operated leg are significant clinical barriers for patients and their caregivers following TKA (2-4). Specifically, quadriceps atrophy and weakness compromise balance (5), reduce functional mobility $(6,7)$, and increase the risk of falls (8). Tests of functional mobility consistently demonstrate marginal improvements following TKA surgery (9-11). Functional tasks such as level walking and stair climbing, which is considered a high fall-risk activity, are chronically deficient in patients following TKA as compared with age- and gender-matched adults (10, 11). A recent report suggests that early postoperative function may predict the speed of functional recovery and the overall success of rehabilitation (12). Evidence suggests that acute weakness in the nonoperated limb following TKA is related to poorer func-

Conflict of interest: The authors have declared that no conflict of interest exists. Citation for this article: J Clin Invest. 2013;123(11):4654-4666. doi:10.1172/JCI70160. tional outcomes in the long term (13), and maintaining greater muscle volume in the operated extremity is essential to maximize muscle strength $(14,15)$. Published reports demonstrate that after a peak in functional recovery 6 months after TKA, there is an acceleration of functional decline due to quadriceps weakness that outpaces normal aging and is not attributable to a lack of range of motion or pain $(7,16-18)$. For older adults, acute muscle atrophy and weakness are particularly debilitating, exacerbating underlying issues related to sarcopenia, defined as the chronic loss of muscle mass and function associated with normal aging $(19,20)$. Sarcopenia is related to physical disability (21) and increased risk of home care (22), nursing home placement (23), and hospitalization (24). Health care costs due to sarcopenia in the U.S. in 2000 totaled $\$ 18.5$ billion (25). Thus, mitigating quadriceps-specific muscle atrophy and weakness appears to be a prudent undertaking with the potential to improve quality of life for millions of older adults following TKA.

A role for essential amino acid (EAA) treatment in mitigating muscle atrophy has previously been proposed but has not been thoroughly tested in a clinical population (26). A recent 


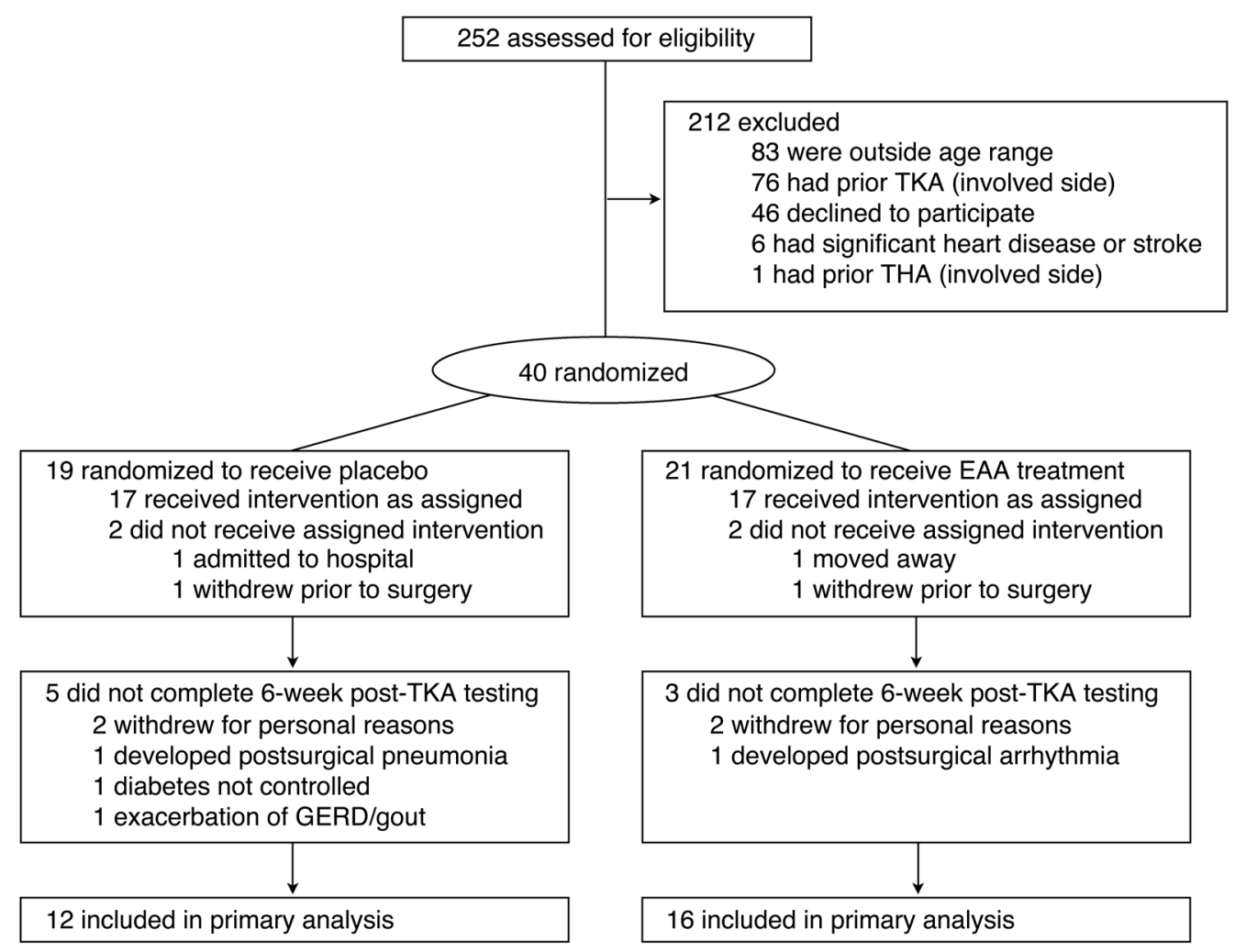

Figure 1

Study flow. Random assignments to treatment group, reasons for exclusion and withdrawal, and study completion.

study in healthy older women showed that 3 months of daily EAA supplementation increased lean body mass, potentially by chronically elevating the basal rates of muscle protein synthesis, but had no effect on strength (27). Conversely, a similarly designed study conducted in older men with type 2 diabetes failed to increase lean body mass or strength following 3 and 6 months of daily ingestion of the branched-chain amino acid leucine $(28,29)$. Thus, to our knowledge, a clinical investigation using a double-blind, placebo-controlled approach has never been performed to test the hypothesis that EAA supplementation mitigates muscle atrophy following TKA. In our study, EAA supplementation appeared to be safe, and no subjects withdrew because of problems with supplement ingestion. Given the history of dietary supplementations in general and amino-acid supplementation in particular, it is important that research in this area be able to demonstrate the safety of EAA supplementation.

The purpose of this randomized clinical trial was to measure changes in muscle volume and functional mobility in two groups (EAA versus placebo) of older adults before and after TKA. Our hypothesis is that twice-daily ingestion of $20 \mathrm{~g}$ of EAAs between meals for 1 week before and 2 weeks after TKA would attenuate muscle loss and help restore functional mobility. Such results would have an important positive public health impact, as they are clinically meaningful and broadly applicable and can be readily translated into clinical use, thereby serving as a proof of concept for EAA treatment in the mitigation of muscle atrophy in a clinical setting.

\section{Results}

Demographics and sample description. A flow diagram illustrating the derivation of the study sample is presented in Figure 1, and subject baseline demographic and clinical characteristics for each group are provided in Tables 1 and 2. Data from a total of 28 participants $(\mathrm{EAA}=16$; placebo $=12)$ were available for analysis and analyzed according to the original group assignment. The sample consisted of $67.9 \%$ females, mean age was $69.14 \pm 0.96$ years (mean \pm $\mathrm{SE}$ ), mean $\mathrm{BMI}$ was $31.70 \pm 1.21 \mathrm{~kg} / \mathrm{m}^{2}$, mean tourniquet time was $42.46 \pm 1.65$ minutes, and mean length of inpatient hospital stay was $3.18 \pm 0.19$ days. Treatment groups (placebo versus EAA) did not differ significantly by age, BMI, tourniquet time, length of stay, or use of prescription medications (all $P>0.05$ ). After surgery, patients on average had $11.78 \pm 0.93$ physical therapy treatments. The number of treatments did not differ significantly between the two treatment conditions (mean visits $=11.27 \pm 1.17$ EAA vs. $12.30 \pm 1.44$ placebo) during the 6 -week post-TKA period of data collection. There were no significant between-group mean differences in initial levels of muscle volume and strength, with the exception of mid-thigh intermuscular adipose tissue (IMAT) in the nonoperated leg $(61.53 \pm 7.60$ EAA vs. $39.75 \pm 4.81$ placebo, $P<0.05)$. Statin use, BMI, and energy intake were not significantly associated with changes in muscle volume and strength outcomes. Repeated measures analyses of variance results showed that there were significant changes in muscle volume and strength outcomes over time, regardless of treatment condition. Quadriceps volume and strength significantly changed in the operated leg from baseline to 2 weeks after TKA, from baseline to 6 weeks after TKA, and 
Table 1

Patient characteristics by treatment condition ${ }^{A}$

\begin{tabular}{|c|c|c|c|}
\hline Characteristics & Placebo & EAA & $P$ \\
\hline$\%$ Female & 67 & 69 & \\
\hline Age (yr) & $70 \pm 5$ & $68 \pm 5$ & 0. \\
\hline Height (m) & $1.65 \pm 0.08$ & $1.67 \pm 0.10$ & \\
\hline Weight (kg) & $79 \pm 13$ & $96 \pm 28$ & \\
\hline $\mathrm{BMI}, \mathrm{kg} / \mathrm{m}^{2}$ & $29 \pm 3$ & $34 \pm 7$ & \\
\hline Tourniquet time (min) & $43 \pm 13$ & $42 \pm 5$ & \\
\hline Length of stay (days) & $3.2 \pm 1$ & $3.2 \pm 1$ & \\
\hline Baseline mean steps/day & $4,369 \pm 2,176$ & $3,826 \pm 2,414$ & 0.6 \\
\hline Baseline mean pain rating & $4 \pm 2$ & $4 \pm 2$ & \\
\hline \multicolumn{4}{|l|}{ Baseline nutrients } \\
\hline \multicolumn{4}{|l|}{ Protein intake } \\
\hline g/day & $65 \pm 6$ & $69 \pm 6$ & \\
\hline $\mathrm{g} / \mathrm{kg}$ of body weight & $0.83 \pm 0.09$ & $0.79 \pm 0.08$ & \\
\hline Fat intake (g/day) & $52 \pm 15$ & $58 \pm 15$ & 0. \\
\hline Carbohydrate intake ( $\mathrm{g} /$ day) & $168 \pm 46$ & $178 \pm 48$ & \\
\hline Calories (kcal/day) & $1,396 \pm 282$ & $1,546 \pm 270$ & \\
\hline $\mathrm{kcal} / \mathrm{kg} / \mathrm{day}$ & $18 \pm 1$ & $17 \pm 1$ & \\
\hline \multicolumn{4}{|l|}{ 2-wk postoperative nutrients } \\
\hline \multicolumn{4}{|l|}{ Protein intake } \\
\hline g/day & $49 \pm 7^{B}$ & $62 \pm 6$ & \\
\hline $\mathrm{g} / \mathrm{kg}$ of body weight & $0.63 \pm 0.09 \mathrm{~B}$ & $0.70 \pm 0.08$ & \\
\hline Fat intake (g/day) & $34 \pm 5$ & $47 \pm 5$ & \\
\hline Carbohydrate intake (g/day) & $134 \pm 20$ & $155 \pm 17$ & \\
\hline Calories (kcal/day) & $1,000 \pm 145^{B}$ & $1,348 \pm 123$ & 0. \\
\hline $\mathrm{kcal} / \mathrm{kg} / \mathrm{day}$ & $13 \pm 2^{B}$ & $15 \pm 2$ & \\
\hline \multicolumn{4}{|l|}{ 6-wk postoperative nutrients } \\
\hline \multicolumn{4}{|l|}{ Protein intake } \\
\hline g/day & $67 \pm 7$ & $66 \pm 6$ & \\
\hline $\mathrm{g} / \mathrm{kg}$ of body weight & $0.86 \pm 0.09$ & $0.75 \pm 0.09$ & \\
\hline Fat intake (g/day) & $56 \pm 5$ & $52 \pm 5$ & \\
\hline Carbohydrate intake (g/day) & $186 \pm 16$ & $164 \pm 15$ & \\
\hline Calories (kcal/day) & $1,516 \pm 138$ & $1,504 \pm 127$ & \\
\hline $\mathrm{kcal} / \mathrm{kg} / \mathrm{day}$ & $19 \pm 1$ & $17 \pm 2$ & \\
\hline
\end{tabular}

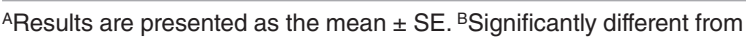
baseline within the treatment condition.

from 2 to 6 weeks after TKA (all $P<0.05$ ). In the nonoperated leg, quadriceps volume significantly changed from baseline to 2 weeks after TKA and from 2 to 6 weeks after TKA (both $P<0.05$ ). Quadriceps strength in the nonoperated leg did not significantly change over time $(P>0.05)$. Hamstring volume in the operated and nonoperated legs significantly changed from baseline to 2 weeks after TKA and from baseline to 6 weeks after TKA (both $P<0.05)$. Hamstring strength significantly changed from baseline to 2 weeks after TKA and from 2 to 6 weeks after TKA in the operated leg (both $P<0.05$ ), but did not significantly change in the nonoperated leg. Mid-thigh IMAT did not significantly change over time in either leg. The following sections present the results of the treatment-conditioned differences.

Food diaries. Table 1 presents nutrient intake by group at baseline, 2 weeks, and 6 weeks after TKA. Self-reported food diaries were obtained at baseline and 2 and 6 weeks after TKA. Dietary protein intake, fat intake, carbohydrate intake, and calorie intake did not significantly differ (all $P>0.05$ ) across the two treatment conditions at any time point (Table 1 ). There was a significant drop in calories from baseline to 2 weeks after TKA for the placebo group (kcal/day: $-30 \pm 7 \%, t=-3.96, P=0.002 ; \mathrm{kcal} / \mathrm{kg} / \mathrm{day}$ :
$-30 \pm 7 \%, t=-3.82, P=0.003)$ but not for the EAA group (kcal/day: $-12 \pm 8 \%, t=-1.13, P=0.140 ; \mathrm{kcal} / \mathrm{kg} /$ day: $-12 \pm 8 \%, t=-0.83$, $P=0.212)$. The change from baseline to 2 weeks after TKA did not differ by condition $(P>0.05)$. We found no significant changes from baseline to 6 weeks after TKA or differences by condition for $\mathrm{kcal} /$ day or $\mathrm{kcal} / \mathrm{kg} /$ day. Daily fat intake at 2 weeks after TKA decreased, but not significantly so, for both placebo $(-29 \pm 13 \%$ change from baseline, $t=-1.80, P=0.055)$ and EAA groups $(-0.4 \pm 11 \%$ change from baseline, $t=-1.41, P=0.092)$, and there was no difference between conditions in the decrease in fat consumption (all $P>0.05$ ). Neither group significantly changed daily fat intake from baseline to 6 weeks after TKA (all $P>0.05$ ). Carbohydrate intake per day did not change significantly from baseline to 2 weeks or 6 weeks after TKA (all $P>0.05$ ). We found a significant drop in protein from baseline to 2 weeks after TKA in the placebo group (protein/day: $-19 \pm 9 \%, t=-2.08, P=0.036$; protein $/ \mathrm{kg} /$ day: $19 \pm 9 \%, t=-2.52, P=0.018$ ), but not in the EAA group (protein/day: $-11 \pm 7 \%, t=-1.14, P=0.139$; protein $/ \mathrm{kg} /$ day: $-11 \pm 7 \%$, $t=-1.40, P=0.093)$. The change from baseline to 2 weeks after TKA did not differ by condition $(P>0.05)$. No changes from baseline to 6 weeks after TKA or differences by condition were found for protein or protein $/ \mathrm{kg}$. Dietary EAAs could not be estimated.

Pain. Patients rated perceived pain on a 0 to 10 scale $(0=$ no pain) each morning and evening for 1 week before surgery and for 2 weeks following surgery. Across all patients, the mean pain ratings were $4 \pm 4$ preoperation and $5 \pm 1$ postoperation, representing a significant increase $(t=-3.01$ [degrees of freedom $=26$ ], $P=0.006)$. Preoperative and postoperative mean pain ratings did not differ significantly across the two treatment conditions: the respective preoperative and postoperative means were $4 \pm 1$ and $5 \pm 1$ for the placebo group and $4 \pm 1$ and $5 \pm 1$ for the EAA group.

Activity. Patients' activity as determined by analysis of available pedometer data $(n=6$ placebo, and $n=9 \mathrm{EAA})$ indicated that the two treatment conditions did not differ in average steps per day before TKA (mean steps/day = 4,369 \pm 889 placebo vs. 3,826 \pm 809 EAA, $t$ [degrees of freedom $=13$ ] $=0.44, P=0.67)$ or after TKA (mean steps $/$ day $=1,891 \pm 546$ placebo vs. $1,485 \pm 192$ EAA, $t$ [degrees of freedom $=13]=0.82, P=0.43)$.

Muscle volume. Figure 2 depicts raw quadriceps and hamstrings and adductor muscle volume. Tables 3 and 4 present absolute (raw) and adjusted quadriceps and hamstrings and adductor volume values 2 weeks and 6 weeks after TKA, respectively. Two weeks after TKA, EAA treatment reduced quadriceps atrophy in the operated quadriceps $(-14.3 \pm 3.6 \%$ change from baseline placebo vs. $-3.6 \pm 3.1 \% \mathrm{EAA} ; F=5.16, P=0.036)$ and in the nonoperated quadriceps $(-9.7 \pm 2.5 \%$ change from baseline placebo vs. $-3.3 \pm$ $2.1 \%$ EAA; $F=3.70, P=0.07)$. Six weeks after TKA, EAA treatment reduced muscle atrophy in the operated quadriceps $(-18.4 \pm$ $2.3 \%$ change from baseline placebo vs. $-6.2 \pm 2.2 \% \mathrm{EAA} ; F=14.14$, $P=0.001)$ and in the nonoperated quadriceps $(-9.6 \pm 1.8 \%$ placebo vs. $-2.9 \pm 1.8 \% \mathrm{EAA} ; F=6.78, P=0.016)$.

Results for hamstrings and adductors (grouped) were similar to those for the quadriceps, with significantly less atrophy in the EAA group versus the placebo group 6 weeks postoperation. Two weeks postoperation, EAAs reduced muscle atrophy in the operated hamstrings and adductors $(-15.1 \pm 2.4 \%$ change from baseline placebo vs. $-11.0 \pm 2.0 \% \mathrm{EAA} ; F=1.54, P=0.23)$ and in the nonoperated hamstrings and adductors $(-8.9 \pm 2.3 \%$ change from baseline placebo vs. $-4.4 \pm 1.9 \% \mathrm{EAA} ; F=2.15, P=0.16$ ). Six weeks postoperation, EAA treatment reduced muscle atrophy 
Table 2

Medications by treatment condition ${ }^{\mathrm{A}}$

\begin{tabular}{lccc}
\hline Medications $^{B}$ & Placebo & EAA & $\boldsymbol{P}$ \\
Acetaminophen & $25 \%$ & $31 \%$ & 0.72 \\
Anticoagulant & $16 \%$ & $13 \%$ & 0.76 \\
Antidiarrhea & $8 \%$ & $0 \%$ & 0.24 \\
Baby aspirin & $25 \%$ & $31 \%$ & 0.72 \\
Blood pressure & $50 \%$ & $50 \%$ & 1.00 \\
Calcium & $17 \%$ & $31 \%$ & 0.38 \\
Cardiac glycoside & $8 \%$ & $0 \%$ & 0.24 \\
COPD & $8 \%$ & $19 \%$ & 0.44 \\
Diabetes & $8 \%$ & $6 \%$ & 0.83 \\
GI (ulcer/GERD) & $8 \%$ & $38 \%$ & 0.08 \\
Glucosamine & $25 \%$ & $25 \%$ & 1.00 \\
Estrogen & $17 \%$ & $12 \%$ & 0.76 \\
Muscle relaxant & $0 \%$ & $6 \%$ & 0.38 \\
NSAIDB & $42 \%$ & $25 \%$ & 0.37 \\
Osteoporosis & $8 \%$ & $0 \%$ & 0.24 \\
Pain reliever & $33 \%$ & $50 \%$ & 0.38 \\
Statin & $50 \%$ & $25 \%$ & 0.19 \\
SNRI & $8 \%$ & $0 \%$ & 0.24 \\
SSRI & $8 \%$ & $6 \%$ & 0.84 \\
Non-SNRI/SSRI antidepressant & $0 \%$ & $13 \%$ & 0.22 \\
Thyroid & $0 \%$ & $6 \%$ & 0.38 \\
Vitamin D & $42 \%$ & $31 \%$ & 0.57 \\
\hline
\end{tabular}

${ }^{A}$ Results reported as a mean percentage change from baseline. ${ }^{B}$ Medications withheld 1 week prior to surgery include NSAID and aspirin. These medications were not started again until 2 weeks postoperation. NSAID use did not covary with the change in muscle volume, strength change, or functional mobility. COPD, chronic obstructive pulmonary disease; GERD, gastroesophageal reflux disease; GI, gastrointestinal; SNRI, serotonin and norepinephrine reuptake inhibitors; SSRI, selective serotonin reuptake inhibitors.

in the operated hamstrings and adductors $(-18.2 \pm 1.8 \%$ change from baseline placebo vs. $-7.5 \pm 1.7 \% \mathrm{EAA} ; F=18.10, P<0.001)$ and in the nonoperated hamstrings and adductors $(-8.3 \pm 1.4 \%$ placebo vs. $-1.6 \pm 1.3 \% \mathrm{EAA} ; F=11.87, P=0.002)$. A representative MR image for the operated mid-thigh region of interest is provided in Figure 3.

IMAT volume. Tables 3 and 4 present absolute (raw) and adjusted IMAT values 2 weeks and 6 weeks after TKA, respectively. Analyses of MRI-measured mid-thigh IMAT data indicated that there was a significant difference between EAA versus placebo groups in the percentage of change from baseline to 6 weeks postoperation, with the EAA group showing an increase and the placebo group a decrease in the operated thigh. Two weeks postoperation, EAA treatment resulted in a mean IMAT change of $-0.12 \pm 2.27 \%$ from baseline in the operated mid-thigh region (versus a placebo change of $-1.82 \pm 2.63 \%$; $F=0.23, P=0.64)$ and $\mathrm{a}+1.27 \pm 2.88 \%$ change from baseline in the nonoperated mid-thigh region (versus a placebo change of $-1.34 \pm$ $3.15 \% ; F=0.38, P=0.55$ ). Six weeks postoperation, EAA treatment resulted in a mean IMAT change of $+4.75 \pm 2.25 \%$ from baseline in the operated mid-thigh region (versus a placebo change of $-3.17 \pm$ $2.35 \%$ from baseline; $F=5.78, P=0.025)$ and $a+1.14 \pm 2.29 \%$ change from baseline in the nonoperated mid-thigh region (versus a placebo change of $-3.29 \pm 2.39 \%$ from baseline; $F=1.76, P=0.20$ ).

Muscle strength. Tables 3 and 4 present absolute (raw) and adjusted quadriceps and hamstring strength values 2 weeks and 6 weeks after TKA, respectively. Six weeks postoperation, EAA increased operated isometric extensor strength at 45 degrees $(-15.5 \pm 6.6 \%$ change from baseline placebo vs. $+6.5 \pm 6.9 \%$ EAA; $F=5.16, P=0.036)$ and at 60 degrees $(-25.9 \pm 9.8 \%$ change from baseline placebo vs. $+4.5 \pm 9.4 \% \mathrm{EAA} ; F=4.83, P=0.039)$. Two weeks postoperation, operated isometric flexor strength loss at 45 degrees was significantly greater for the placebo group $(-59.1 \pm 10.9 \%$ change from baseline placebo vs. $-27.3 \pm 9.5 \%$ EAA; $F=4.81, P<0.05)$, but this effect became nonsignificant when dietary protein intake was added to the model. Two weeks after TKA, there was no significant treatment group difference at 60 degrees $(-51.7 \pm 11.2 \%$ change from baseline placebo vs. $-30.3 \pm$ $11.2 \%$ EAA; $F=1.82, P=0.20)$. Six weeks after TKA, there were no significant group differences in hamstring isometric strength at either 45 or 60 degrees.

Functional mobility. Figure 4 presents functional mobility results for timed up-and-go (TUG), stair-climb up, and stair-climb down tests 6 weeks after TKA. Six weeks after TKA, EAA treatment preserved the up-and-go test time $(31.9 \pm 10.2 \%$ change from baseline placebo vs. $-4.0 \pm 9.5 \% \mathrm{EAA} ; F=6.42, P=0.019)$. EAAs reduced the stair-climb-up time 2 weeks after TKA $(205.9 \pm 32.8 \%$ change from baseline placebo vs. $94.6 \pm 27.2 \% \mathrm{EAA} ; F=6.69, P=0.018)$ and 6 weeks after TKA $(51.9 \pm 15.9 \%$ change from baseline placebo vs. $-7.3 \pm 15.3 \%$ EAA; $F=6.99, P=0.015)$. EAAs had no effect on the stair-climb-down time 2 weeks after TKA $(211.2 \pm 52.7 \%$ change from baseline placebo vs. $118.6 \pm 45.5 \% \mathrm{EAA} ; F=1.75, P=0.20)$. However, EAAs significantly reduced the stair-climb-down time 6 weeks after TKA $(53.9 \pm 13.5 \%$ change from baseline placebo vs. $0.05 \pm 13.5 \%$ EAA; $F=7.71, P=0.011)$. EAAs had no effect on the 6 -minute-walk distance 2 weeks after TKA $(-35.7 \pm 9.4 \%$ change from baseline placebo vs. $-21.0 \pm 7.5 \% \mathrm{EAA} ; F=1.49, P=0.24$ ), and EAAs had no effect on the 6 -minute-walk distance 6 weeks after TKA $(-6.8 \pm 6.6 \%$ change from baseline placebo vs. $8.93 \pm 6.1 \%$ EAA; $F=2.94, P=0.10)$.

Multilevel models. Multilevel model (MLM) results are summarized in Table 5. In separate models for the operated and nonoperated legs, the postoperative baseline change in mid-quadriceps muscle atrophy was significantly associated with a change in functional mobility and dietary protein over time. More protein intake and greater functional mobility were related to less atrophy. For the operated extremity, across the full sample, individuals' within-person deviations from their average TUG scores and protein intake were positively associated with a change in quadriceps atrophy $(P=0.021$ and $P=0.001$, respectively); that is, those with increasing protein intake and improving TUG scores tended to have less decrease in muscle volume. In addition, operated quadriceps muscle atrophy significantly decreased the postoperative baseline $(P<0.001)$, and there was a significant group-by-time interactive effect $(P=0.001)$ favoring EAAs (i.e., more muscle atrophy in the placebo condition over time). Followup analyses of each treatment group separately indicated that EAA supplementation was largely responsible for the TUG and protein intake effects $(P=0.025$ and $P=0.01$, respectively, in the EAA condition; both $P>0.05$ in the placebo condition). In the placebo group only, we observed significant postoperative baseline decreases in mid-quadriceps muscle volume $(P<0.001)$.

For the nonoperated extremity, across the full sample, individuals' within-person deviations from their average protein intake were positively associated with a change in quadriceps atrophy $(P=0.031)$ such that increasing protein intake related 

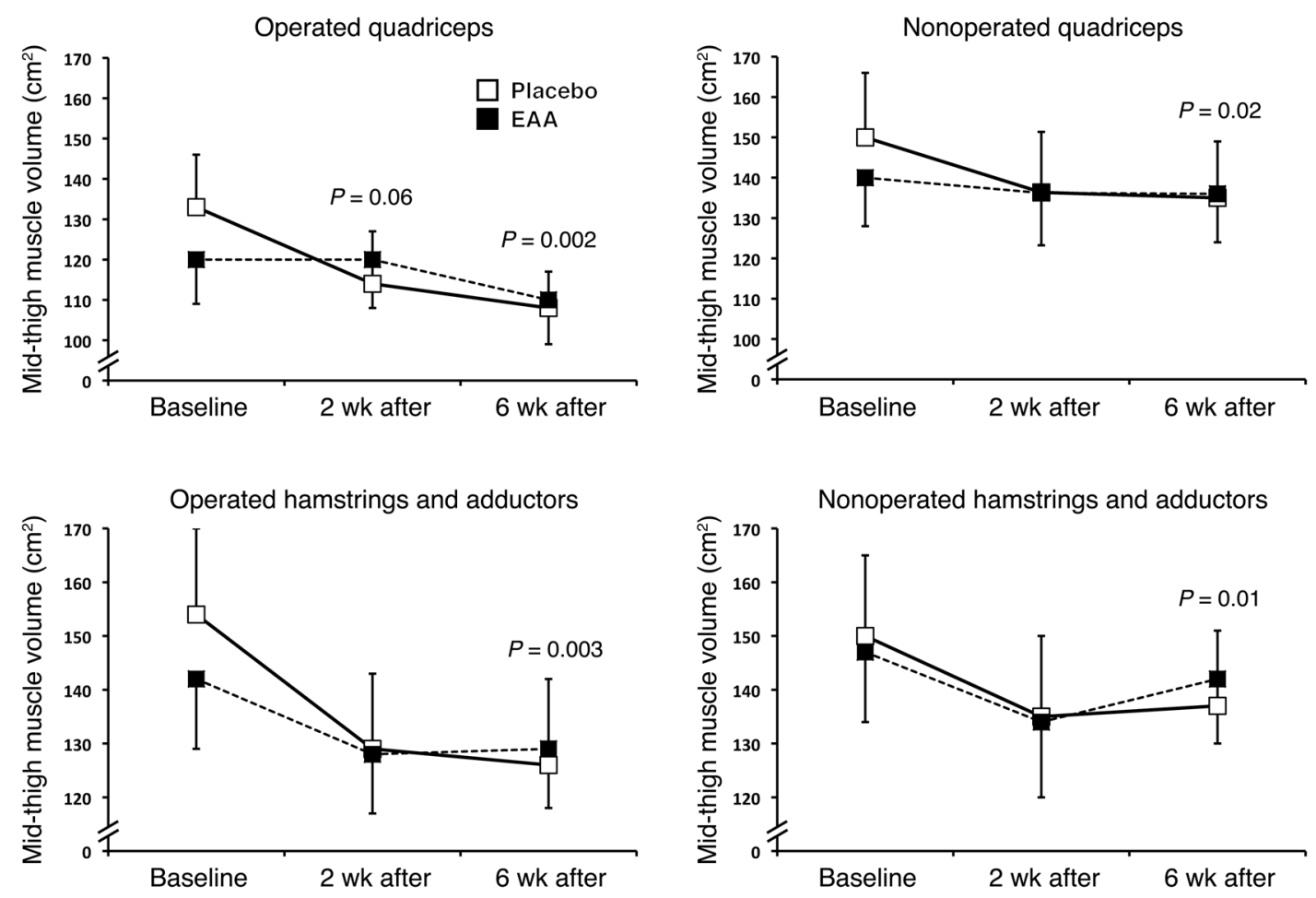

Figure 2

Muscle atrophy. Raw values from baseline for quadriceps and hamstrings and adductor muscle loss between groups. EAA treatment attenuated operated (TKA) quadriceps atrophy by 4.6 -fold versus placebo 2 weeks postoperation. EAAs also mitigated operated quadriceps and hamstrings and adductor muscle atrophy by 3-fold (quadriceps) and 2.2-fold (hamstrings and adductors) at 6 weeks postoperation and by 3-and 4-fold in the quadriceps and hamstrings and adductors, respectively, in the nonoperated thigh. Mid-thigh muscle volume was measured with Analyze version 11.0 software. Values are the mean \pm SEM. Placebo group, $n=12$; EAA group, $n=16$.

to less decreasing muscle volume. Midsection values significantly decreased over time $(P<0.001)$, and there was a significant group-by-time interactive effect $(P=0.025)$ favoring EAA supplementation (i.e., less muscle volume loss in the treatment condition over time). Followup analyses of each treatment group separately revealed a significant negative association between the stair-climb-up test in the EAA group $(P=0.028)$, indicating that those with improving stair-ascent times had less decreasing muscle volume. In both followup models, there was a significant time effect, indicating that muscle atrophy occurred in the nonoperated thigh over time, but the stronger effect was in the placebo group $(P=0.005)$ compared with the EAA group $(P=0.05)$, indicating that atrophy in this thigh was greater in the placebo group.

Additional MLMs examined the effects of time-specific functional measures on time-specific quadriceps muscle volume. Across the full sample, higher scores on functional tests and greater protein intake were associated with greater muscle volume at any given time point in the operated leg only, as follows: TUG $(F=4.47, P=0.041), 6$-minute walk $(F=5.31, P=0.026)$, and protein intake $(F=8.33, P=0.006)$.

Safety. Four patients withdrew from the study for personal reasons. Four were removed from the study due to postsurgical health issues: pneumonia, uncontrolled diabetes, worsening of GERD/ gout, and arrhythmia. None of the subjects withdrew from the study because of issues related to the supplement. There were no adverse events reported by the research staff or investigators.

\section{Discussion}

This clinical trial tested the hypothesis that 21 days of EAA supplementation would mitigate muscle atrophy and mobility impairments in a patient population of older adults (60-80 years of age) following TKA. Results showed that twice-daily ingestion of $20 \mathrm{~g}$ of EAAs for 1 week before and 2 weeks after ( 21 days total) TKA limited bilateral quadriceps and hamstring atrophy by 2- to 4.6fold at 6 weeks after TKA and may explain the earlier recovery of functional mobility (return to baseline) versus placebo. To our knowledge, this is the first clinical study to demonstrate that EAA supplementation mitigated muscle atrophy and accelerated the return of functional mobility in older adults and serves as a proof of principle for the use of EAA supplementation to attenuate muscle loss in older TKA patients.

The mechanisms underlying the reduction in the magnitude of muscle atrophy in the EAA group are unclear but may involve the timing of supplement ingestion. Prior to surgery, the subjects were instructed to ingest the supplement at $10 \mathrm{am}$ and again at $2 \mathrm{pm}$ for 7 days, ending the day before TKA. During inpatient physical therapy, which occurred at approximately 9 am and 1 pm each day, the subjects ingested the supplement within 1 hour of treatment. Upon discharge, the subjects were instructed to continue their normal schedule if they were not having physical therapy but to follow each therapy session with supplement ingestion. The rationale for this approach was based on prior work showing that EAA ingestion 1 hour after a single bout of resistance exercise (30) was superior to EAA ingestion 1 hour before resistance exercise (31) in stimulat- 
Table 3

Baseline to 2-week postoperative raw and covariate-adjusted descriptive statistics and ANOVA results for muscle volume and strength and IMAT (difference and percentage of change scores ${ }^{A}$ )

\begin{tabular}{|c|c|c|c|c|c|c|c|c|}
\hline & Baseline & 2 wk after TKA & Diff (raw) & Diff (adj) & \% Chg (raw) & $\%$ Chg (adj) & Diff $F(P)$ & $\% \operatorname{Chg} F(P)$ \\
\hline \multicolumn{9}{|c|}{ Mid-thigh quadriceps $\left(\mathrm{cm}^{3}\right)$} \\
\hline \multicolumn{9}{|l|}{ Operated } \\
\hline EAA & $120 \pm 11$ & $120 \pm 12$ & $-4 \pm 5$ & $-3 \pm 5$ & $-4 \pm 3$ & $-3 \pm 3$ & $4.2(0.06)$ & $5.2(0.04)$ \\
\hline Placebo & $133 \pm 13$ & $114 \pm 13$ & $-20 \pm 4$ & $-19 \pm 6$ & $-14 \pm 2$ & $-14 \pm 4$ & & \\
\hline \multicolumn{9}{|c|}{ Nonoperated } \\
\hline EAA & $140 \pm 12$ & $136 \pm 13$ & $-6 \pm 3$ & $-5 \pm 3$ & $-3 \pm 2$ & $-3 \pm 2$ & $2.6(0.13)$ & $3.7(0.07)$ \\
\hline Placebo & $150 \pm 16$ & $136 \pm 15$ & $-15 \pm 3$ & $-13 \pm 4$ & $-10 \pm 2$ & $-10 \pm 3$ & & \\
\hline \multicolumn{9}{|c|}{$\begin{array}{l}\text { Mid-thigh hamstrings } \\
\text { and adductors }\left(\mathrm{cm}^{3}\right)\end{array}$} \\
\hline \multicolumn{9}{|l|}{ Operated } \\
\hline EAA & $142 \pm 13$ & $128 \pm 11$ & $-17 \pm 4$ & $-17 \pm 5$ & $-11 \pm 2$ & $-11 \pm 2$ & $0.5(0.50)$ & $1.5(0.23)$ \\
\hline Placebo & $154 \pm 17$ & $129 \pm 14$ & $-25 \pm 5$ & $-22 \pm 5$ & $-15 \pm 2$ & $-15 \pm 2$ & & \\
\hline \multicolumn{9}{|c|}{ Nonoperated } \\
\hline EAA & $147 \pm 13$ & $134 \pm 14$ & $-13 \pm 6$ & $-13 \pm 6$ & $-4 \pm 1$ & $-4 \pm 2$ & $0.1(0.77)$ & $2.2(0.16)$ \\
\hline Placebo & $150 \pm 15$ & $135 \pm 15$ & $-15 \pm 4$ & $-16 \pm 7$ & $-9 \pm 2$ & $-9 \pm 2$ & & \\
\hline \multicolumn{9}{|c|}{ Mid-thigh IMAT $\left(\mathrm{cm}^{3}\right)$} \\
\hline \multicolumn{9}{|c|}{ Operated } \\
\hline EAA & $66 \pm 7$ & $64 \pm 7$ & $-1 \pm 1$ & $-1 \pm 1$ & $-1 \pm 2$ & $0 \pm 2$ & $0.1(0.74)$ & $0.2(0.64)$ \\
\hline Placebo & $46 \pm 7$ & $44 \pm 6$ & $-2 \pm 2$ & $-1 \pm 2$ & $-1 \pm 3$ & $-2 \pm 3$ & & \\
\hline \multicolumn{9}{|c|}{ Nonoperated } \\
\hline EAA & $62 \pm 8^{B}$ & $61 \pm 8$ & $0 \pm 1$ & $0 \pm 1$ & $1 \pm 2$ & $1 \pm 3$ & $0.5(0.49)$ & $0.4(0.55)$ \\
\hline Placebo & $40 \pm 5$ & $37 \pm 4$ & $-1 \pm 2$ & $-1 \pm 2$ & $-2 \pm 3$ & $-1 \pm 3$ & & \\
\hline \multicolumn{9}{|c|}{ Isometric strength } \\
\hline \multicolumn{9}{|c|}{$45^{\circ}$ Quadriceps (N) } \\
\hline \multicolumn{9}{|c|}{ Operated } \\
\hline EAA & $87 \pm 9$ & $45 \pm 6$ & $-32 \pm 11$ & $-34 \pm 11$ & $-35 \pm 12$ & $-37 \pm 14$ & $0.0(0.85)$ & $0.0(0.92)$ \\
\hline Placebo & $87 \pm 15$ & $36 \pm 7$ & $-49 \pm 16$ & $-30 \pm 14$ & $-50 \pm 7$ & $-39 \pm 14$ & & \\
\hline \multicolumn{9}{|c|}{ Nonoperated } \\
\hline EAA & $100 \pm 7$ & $100 \pm 10$ & $9 \pm 5$ & $9 \pm 5$ & $11 \pm 6$ & $11 \pm 5$ & $2.5(0.14)$ & $2.5(0.14)$ \\
\hline Placebo & $112 \pm 16$ & $100 \pm 12$ & $-14 \pm 6$ & $-4 \pm 7$ & $-10 \pm 4$ & $-4 \pm 8$ & & \\
\hline \multicolumn{9}{|c|}{$45^{\circ}$ Hamstrings (N) } \\
\hline \multicolumn{9}{|l|}{ Operated } \\
\hline EAA & $41 \pm 4$ & $27 \pm 4$ & $-12 \pm 3$ & $-11 \pm 3$ & $-6 \pm 3$ & $0 \pm 6$ & $1.3(0.27)$ & $1.0(0.34)$ \\
\hline Placebo & $39 \pm 6$ & $22 \pm 5$ & $-19 \pm 4$ & $-17 \pm 3$ & $-8 \pm 7$ & $-9 \pm 6$ & & \\
\hline \multicolumn{9}{|c|}{ Nonoperated } \\
\hline EAA & $54 \pm 11$ & $42 \pm 5$ & $-14 \pm 14$ & $-1 \pm 3$ & $-5 \pm 11$ & $3 \pm 7$ & $1.0(0.42)$ & $1.1(0.32)$ \\
\hline Placebo & $45 \pm 6$ & $42 \pm 6$ & $-4 \pm 2$ & $-4 \pm 3$ & $-9 \pm 6$ & $-8 \pm 9$ & & \\
\hline \multicolumn{9}{|c|}{$60^{\circ}$ Quadriceps (N) } \\
\hline \multicolumn{9}{|l|}{ Operated } \\
\hline EAA & $89 \pm 9$ & $41 \pm 6$ & $-42 \pm 10$ & $-42 \pm 11$ & $-46 \pm 10$ & $-46 \pm 9$ & $0.2(0.65)$ & $0.4(0.53)$ \\
\hline & $97 \pm 16$ & $33 \pm 8$ & $-67 \pm 19$ & $-50 \pm 14$ & $-63 \pm 5$ & $-56 \pm 12$ & & \\
\hline \multicolumn{9}{|c|}{ Nonoperated } \\
\hline EAA & $109 \pm 9$ & $109 \pm 10$ & $7 \pm 6$ & $10 \pm 7$ & $7 \pm 6$ & $10 \pm 5$ & $9.5(0.01)$ & $10.5(0.01)$ \\
\hline Placebo & $126 \pm 18$ & $105 \pm 12$ & $-29 \pm 9$ & $-28 \pm 10$ & $-20 \pm 5$ & $-22 \pm 8$ & & \\
\hline $60^{\circ}$ Hams & & & & & & & & \\
\hline Operated & & & & & & & & \\
\hline EAA & $35 \pm 3$ & $24 \pm 5$ & $-11 \pm 3$ & $-10 \pm 3$ & $-33 \pm 8$ & $-30 \pm 11$ & $0.2(0.70)$ & $1.8(0.20)$ \\
\hline Placebo & $36 \pm 5$ & $19 \pm 6$ & $-16 \pm 5$ & $-12 \pm 4$ & $-54 \pm 12$ & $-52 \pm 11$ & & \\
\hline Nonoperat & & & & & & & & \\
\hline EAA & $41 \pm 4$ & $40 \pm 4$ & $1 \pm 2$ & $1 \pm 2$ & $-1 \pm 6$ & $2 \pm 6$ & $0.1(0.75)$ & $0.0(0.94)$ \\
\hline Placebo & $42 \pm 5$ & $42 \pm 5$ & $-1 \pm 2$ & $-1 \pm 3$ & $0 \pm 5$ & $1 \pm 6$ & & \\
\hline
\end{tabular}

ADifference scores were calculated as followup minus baseline. Note that the change in protein intake was covaried in all models. ${ }^{\mathrm{B}}$ Significant betweengroup baseline difference $(P<0.05)$. Because of some missing data, the mean difference score and percentage change values are not exact reproductions of differences in the means at the two time points. adj, adjusted; Chg, change; Diff, difference; N, Newtons. 


\section{Table 4}

Baseline to 6-week postoperative raw and covariate-adjusted descriptive statistics and ANOVA results for muscle volume and strength and IMAT (difference and percentage of change scores ${ }^{A}$ )

\begin{tabular}{|c|c|c|c|c|c|c|c|c|}
\hline & Baseline & 6 wk after TKA & Diff (raw) & Diff (adj) & \% Chg (raw) & $\%$ Chg (adj) & Diff $F(P)$ & $\% \operatorname{Chg} F(P)$ \\
\hline \multicolumn{9}{|c|}{ Mid-thigh quadriceps $\left(\mathrm{cm}^{3}\right)$} \\
\hline \multicolumn{9}{|l|}{ Operated } \\
\hline EAA & $120 \pm 11$ & $110 \pm 11$ & $-10 \pm 4$ & $-7 \pm 4$ & $-8 \pm 3$ & $-6 \pm 2$ & \multirow[t]{2}{*}{$11.7(0.002)$} & \multirow[t]{2}{*}{$14.1(0.001)$} \\
\hline Placebo & $133 \pm 13$ & $108 \pm 9$ & $-24 \pm 5$ & $-26 \pm 4$ & $-17 \pm 2$ & $-18 \pm 2$ & & \\
\hline \multicolumn{9}{|c|}{ Nonoperated } \\
\hline EAA & $140 \pm 12$ & $136 \pm 12$ & $-5 \pm 2$ & $-4 \pm 3$ & $-3 \pm 1$ & $-3 \pm 2$ & \multirow[t]{2}{*}{$7.2(0.02)$} & \multirow[t]{2}{*}{$6.8(0.02)$} \\
\hline Placebo & $150 \pm 16$ & $135 \pm 14$ & $-15 \pm 2$ & $-15 \pm 3$ & $-9 \pm 2$ & $-10 \pm 2$ & & \\
\hline \multicolumn{9}{|c|}{$\begin{array}{l}\text { Mid-thigh hamstrings } \\
\text { and adductors }\left(\mathrm{cm}^{3}\right)\end{array}$} \\
\hline Operated & & & & & & & & \\
\hline EAA & $142 \pm 13$ & $129 \pm 11$ & $-13 \pm 2$ & $-11 \pm 4$ & $-9 \pm 2$ & $-8 \pm 2$ & \multirow[t]{2}{*}{$11.3(0.003)$} & \multirow{2}{*}{$18.1(<0.001)$} \\
\hline Placebo & $154 \pm 17$ & $126 \pm 16$ & $-27 \pm 5$ & $-29 \pm 4$ & $-18 \pm 2$ & $-18 \pm 2$ & & \\
\hline \multicolumn{9}{|c|}{ Nonoperated } \\
\hline EAA & $147 \pm 13$ & $142 \pm 12$ & $-4 \pm 2$ & $-3 \pm 3$ & $-3 \pm 1$ & $-2 \pm 1$ & \multirow[t]{2}{*}{$7.3(0.01)$} & \multirow{2}{*}{$11.9(0.002)$} \\
\hline Placebo & $150 \pm 15$ & $137 \pm 14$ & $-12 \pm 3$ & $-13 \pm 3$ & $-8 \pm 2$ & $-8 \pm 1$ & & \\
\hline \multicolumn{9}{|c|}{ Mid-thigh IMAT $\left(\mathrm{cm}^{3}\right)$} \\
\hline \multicolumn{9}{|l|}{ Operated } \\
\hline EAA & $66 \pm 7$ & $69 \pm 8$ & $3 \pm 1$ & $3 \pm 2$ & $6 \pm 2$ & $5 \pm 2$ & \multirow[t]{2}{*}{$4.9(0.04)$} & \multirow[t]{2}{*}{$5.8(0.03)$} \\
\hline Placebo & $46 \pm 7$ & $44 \pm 6$ & $-2 \pm 2$ & $-2 \pm 2$ & $-4 \pm 3$ & $-3 \pm 2$ & & \\
\hline \multicolumn{9}{|c|}{ Nonoperated } \\
\hline EAA & $62 \pm 8^{B}$ & $61 \pm 7$ & $0 \pm 1$ & $0 \pm 2$ & $0 \pm 1$ & $1 \pm 2$ & \multirow[t]{2}{*}{$0.5(0.50)$} & $1.8(0.20)$ \\
\hline Placebo & $40 \pm 5$ & $39 \pm 5$ & $0 \pm 2$ & $-1 \pm 11$ & $-2 \pm 4$ & $-3 \pm 2$ & & \\
\hline Isometric & & & & & & & & \\
\hline $45^{\circ}$ Quadri & & & & & & & & \\
\hline Operated & & & & & & & & \\
\hline EAA & $87 \pm 9$ & $81 \pm 7$ & $-5 \pm 6$ & $2 \pm 7$ & $0 \pm 7$ & $7 \pm 7$ & $5.2(0.04)$ & $5.2(0.04)$ \\
\hline Placebo & $87 \pm 15$ & $69 \pm 9$ & $-17 \pm 8$ & $-20 \pm 6$ & $-13 \pm 7$ & $-16 \pm 7$ & & \\
\hline Nonoperat & & & & & & & & \\
\hline EAA & $100 \pm 7$ & $104 \pm 9$ & $6 \pm 5$ & $6 \pm 6$ & $7 \pm 6$ & $7 \pm 6$ & $3.4(0.08)$ & $2.6(0.12)$ \\
\hline Placebo & $112 \pm 16$ & $99 \pm 12$ & $-12 \pm 6$ & $-11 \pm 6$ & $-8 \pm 5$ & $-7 \pm 6$ & & \\
\hline $45^{\circ}$ Hamst & & & & & & & & \\
\hline Operated & & & & & & & & \\
\hline EAA & $41 \pm 4$ & $36 \pm 4$ & $-5 \pm 4$ & $-3 \pm 4$ & $-6 \pm 12$ & $0 \pm 22$ & $0.0(0.93)$ & $0.1(0.80)$ \\
\hline Placebo & $39 \pm 6$ & $36 \pm 6$ & $-1 \pm 5$ & $-4 \pm 4$ & $13 \pm 25$ & $8 \pm 21$ & & \\
\hline Nonoperate & & & & & & & & \\
\hline EAA & $54 \pm 11$ & $47 \pm 4$ & $-9 \pm 12$ & $5 \pm 4$ & $13 \pm 21$ & $28 \pm 17$ & $0.6(0.47)$ & $1.1(0.32)$ \\
\hline Placebo & $45 \pm 6$ & $45 \pm 6$ & $3 \pm 2$ & $1 \pm 4$ & $8 \pm 6$ & $2 \pm 18$ & & \\
\hline $60^{\circ}$ Quadri & & & & & & & & \\
\hline Operated & & & & & & & & \\
\hline EAA & $89 \pm 9$ & $81 \pm 7$ & $-8 \pm 7$ & $-3 \pm 10$ & $-2 \pm 9$ & $5 \pm 9$ & $5.0(0.04)$ & $4.8(0.04)$ \\
\hline Placebo & $97 \pm 16$ & $65 \pm 8$ & $-32 \pm 12$ & $-35 \pm 10$ & $-23 \pm 10$ & $-26 \pm 10$ & & \\
\hline Nonoperate & & & & & & & & \\
\hline EAA & $109 \pm 9$ & $110 \pm 11$ & $3 \pm 6$ & $4 \pm 6$ & $2 \pm 6$ & $2 \pm 6$ & $3.7(0.07)$ & $1.2(0.29)$ \\
\hline Placebo & $126 \pm 18$ & $112 \pm 14$ & $-15 \pm 6$ & $-13 \pm 6$ & $-8 \pm 4$ & $-7 \pm 6$ & & \\
\hline $60^{\circ}$ Hamst & & & & & & & & \\
\hline Operated & & & & & & & & \\
\hline EAA & $35 \pm 3$ & $33 \pm 4$ & $0 \pm 4$ & $1 \pm 4$ & $22 \pm 23$ & $29 \pm 25$ & $1.2(0.29)$ & $0.5(0.50)$ \\
\hline Placebo & $36 \pm 5$ & $30 \pm 4$ & $-4 \pm 4$ & $-6 \pm 4$ & $7 \pm 20$ & $4 \pm 25$ & & \\
\hline Nonoperate & & & & & & & & \\
\hline EAA & $41 \pm 4$ & $43 \pm 4$ & $3 \pm 3$ & $4 \pm 3$ & $13 \pm 11$ & $18 \pm 10$ & $1.5(0.23)$ & $1.2(0.29)$ \\
\hline Placebo & $42 \pm 5$ & $41 \pm 4$ & $0 \pm 2$ & $-1 \pm 3$ & $5 \pm 5$ & $1 \pm 11$ & & \\
\hline
\end{tabular}

ADifference scores were calculated as followup minus baseline. Note that the change in protein intake was covaried in all models. ${ }^{B}$ Significant betweengroup baseline difference $(P<0.05)$. Because of some missing data, the mean difference score and percentage change values are not exact reproductions of differences in the means at the two time points. 


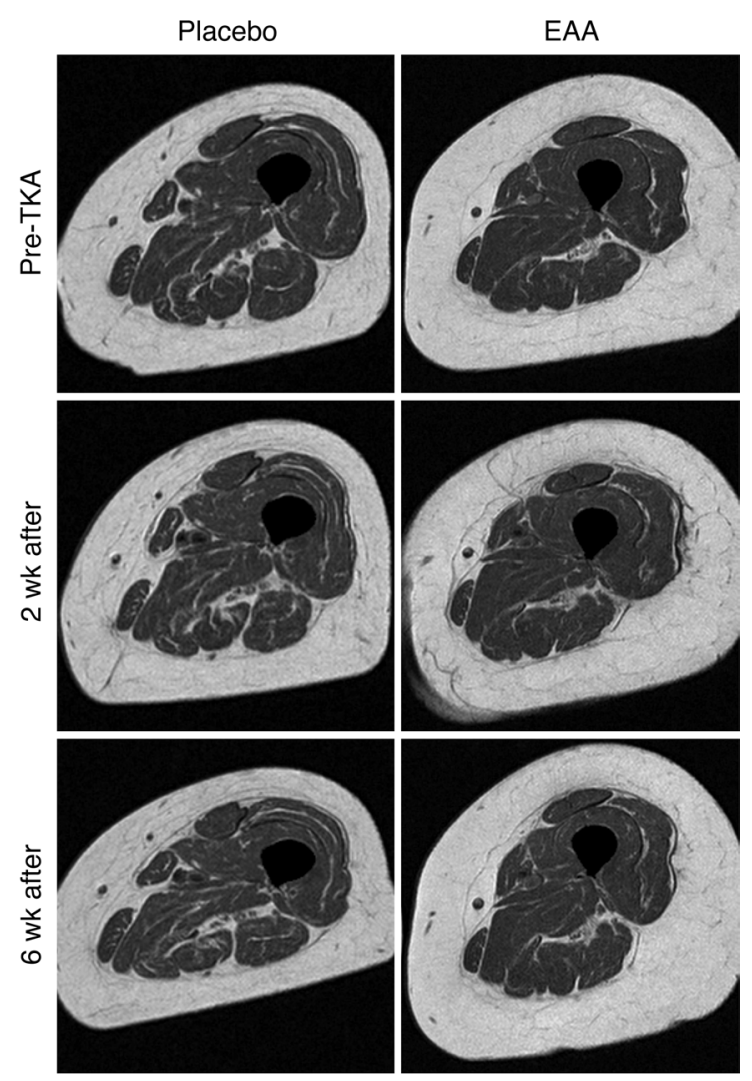

ing muscle protein synthesis. Further support comes from a recent study by Jordan et al. (32) showing that in older adults on an isocaloric, isonitrogenous diet and having controlled levels of activity, the nitrogen balance increased $57 \%$ when protein was consumed immediately after daily exercise as opposed to at rest.

Analysis of the 3-day food logs revealed that energy intake was low at baseline, averaging 1,396 and 1,546 calories consumed per day in the placebo and EAA groups, respectively. While low, others have reported similar values in older healthy (33) adults and older patient populations $(34,35)$. However, while not significantly different between the groups 2 weeks postoperation, relative to baseline, the placebo group demonstrated greater decreases in calorie and protein intake. Intuitively, it is reasonable to surmise that reduced energy and protein intake exacerbated the declines in muscle volume, strength, and functional mobility in the subjects who did not have EAA supplementation. In addition, subjects in the EAA group were substantially heavier, which may have provided additional resistance during ambulation and rehabilitation that could offset muscle loss. Finally, 50\% of the subjects in the placebo group were on statins versus only $25 \%$ of patients in the EAA group. Greater statin use in the placebo group may have influenced our findings, as these drugs have been shown to impair the ability of muscle to adapt appropriately to exercise $(36,37)$. Our finding that energy intake, body mass, and statin use were not statistically associated with changes in muscle volume and strength outcomes may be due to a lack of power to detect those relationships. Further research is needed involving a larger number of patients to better define the potential impact of energy and protein intake, body mass, and the concomitant use of statins on the parameters of muscle mass, strength, and functional mobility following TKA.

\section{Figure 3}

Representative mid-thigh MR images of the operated thigh at baseline (pre-TKA), 2 weeks after TKA, and 6 weeks after TKA for the placebo and EAA groups. Placebo images are from a 71-year-old female, and EAA images are from a 74-year-old female.

Human models of muscle disuse and immobilization have been shown to decrease muscle cross-sectional area by $0.3 \%$ to $0.8 \%$ per day within 4 weeks, likely because of reductions in resting muscle protein synthesis of approximately $60 \%$ and a blunted anabolic response to EAA ingestion of approximately $50 \%$, with little contribution from muscle protein breakdown (38). After TKA, however, patients were not immobilized per se, although their mobility was reduced, and they participated in twice-daily physical therapy beginning on postoperative day 1 in order to regain range of motion and mobility. With this in mind, the subjects in our placebo group demonstrated a $14 \%-15 \%$ loss of quadriceps and hamstrings/adductor muscle volume, respectively, in the operated thigh within 2 weeks of surgery. This corresponds to an atrophy rate of approximately $1 \%$ per day, which, allowing for the widely accepted decrements in resting muscle protein synthesis $(-60 \%)$ and blunted anabolic response to EAAs (-50\%), cannot be explained by changes in synthesis rates alone and suggests an increase in muscle protein breakdown $(38,39)$. Potential explanations may be derived from research by Combaret et al. (40), who found that the defective decrease in muscle protein breakdown induced by protein feeding in older rats could be restored with diets supplemented with leucine for 10 days. Further, Katsanos et al. (41) showed that increasing the concentration of leucine from $1.7 \mathrm{~g}$ to $2.8 \mathrm{~g}$ enhanced the acute anabolic effects of EAA ingestion ( $6.7 \mathrm{~g}$ total) on muscle protein synthesis rates in older adults, which is similar to the $3.6 \mathrm{~g}$ of leucine that subjects in our study ingested twice daily for a total of 21 days. As such, the potential for twice-daily ingestion of leucine $(3.6 \mathrm{~g})$ to decrease whole-body (42) and muscle-specific protein breakdown $(40,43)$ while stimulating synthesis rates $(26)$ is quite interesting and clinically relevant for older adults following TKA. It is important to highlight that our patients stopped ingesting the supplement 2 weeks after TKA and that we only followed them until 6 weeks after TKA, which provides us with a short time frame, considering that muscle loss in the quadriceps of EAA subjects occurred after supplementation ended. While further research is needed to determine the effects of TKA on muscle protein synthesis and breakdown rates at rest and following acute EAA ingestion before and after a supplementation trial of potentially longer duration (i.e., 6 weeks versus 2 weeks postsurgery), our results clearly demonstrate that a reduction in muscle breakdown occurred in the EAA group compared with the placebo group.

Quadriceps weakness before and after TKA is influenced by activation failure, which after surgery may account for over half of the strength loss $(4,15,44,45)$. Our strength results are in agreement with what has been previously reported, which is that the operative leg is generally weaker than the nonoperative extremity prior to surgery and is attributable to arthrogenic inhibition, and strength decreases precipitously following this surgery $(4,15,44$, $45)$. The causes of activation deficits underlying muscle weakness are not well understood but appear to be influenced by degenerative changes in the knee joint preoperatively, incision through the extensor mechanism during TKA, joint effusion before and after surgery, and pain that inhibits the ability of the quadriceps to pro- 


\section{Timed Up and Go}

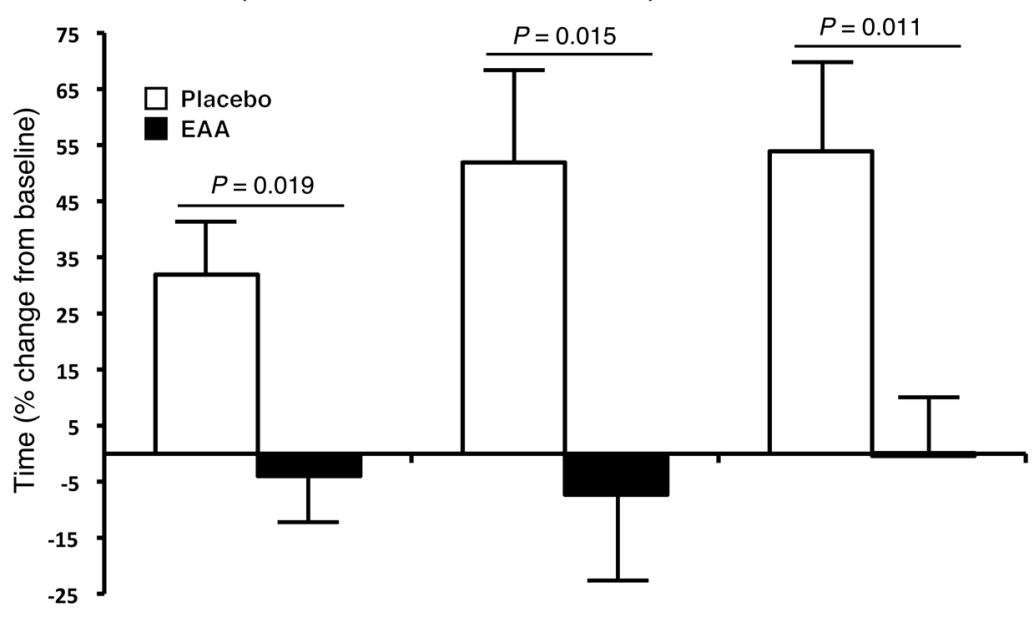

Figure 4

Functional mobility. EAA supplementation accelerated the return of functional mobility versus placebo 6 weeks after TKA. For the TUG test, the subjects began the test in a seated position (all were tested using the same chair), then stood up, walked forward 3 meters across a line that was clearly marked on the floor, then turned around, walked back 3 meters, and sat down in the same chair. Subjects were given verbal instructions to complete the task "as fast and as safely as you can," and the total time was recorded. Total time to go up the stairs and the time to go down were measured. Timing started as soon as the subjects made their initial movements forward or upward. The starting point for the descent portion was when subjects completely faced the stairs. The end point was when both of the subject's feet were at the starting spot on the ground in front of the staircase. All subjects were provided with verbal instructions to complete the test "as fast and as safely as you can." Subjects were timed (seconds) as they ascended 8 steps (stair-climb up) and descended 8 steps (stair-climb down) at baseline and 6 weeks after TKA. The same set of stairs was used for each testing session. Values represent the mean percentage change from baseline \pm SEM. Placebo group, $n=12$; EAA group, $n=16$.

duce maximal force (45). In this context, it is difficult to interpret our results without having included measures of activation deficits in our study. However, when we consider the changes in strength and functional mobility relative to the changes in muscle volume it becomes apparent that acute alterations in muscle volume do not explain the changes in force production. The accumulation of IMAT has recently emerged as a potential source for some of this discrepancy between force production and changes in muscle cross-sectional area (46-48). A recent report from Manini et al. (49) demonstrated that IMAT increases after 4 weeks of reduced physical activity and was associated with reductions in force production. Further, in a group of older adults ( $~ 73$ years of age), high IMAT levels were associated with a diminished force per unit area of muscle tissue (50). Interestingly, IMAT levels demonstrated an increase of $4.75 \%$ in our EAA group over the course of 6 weeks versus a near-opposite $(-3.17 \%)$ reduction in the placebo group. Taken together, it is apparent from our results as well as from others' (19, $51,52)$ that acute alterations in muscle volume do not explain the changes in force production. Clearly, further research into the potential for EAAs to modulate components of muscle structure and function, including activation deficits and IMAT, is warranted.

The results of our MLM analyses show that EAA treatment and dietary protein intake have muscle-sparing effects in the operated and nonoperated quadriceps. They also indicate that EAA treatment and dietary protein intake are associated with better func- tional mobility. Finally, we found that post-TKA changes in muscle and functional mobility covary; that is, patients with less muscle atrophy experienced greater functional mobility. However, while we found that patients with better mobility had lost less muscle volume, the effects of EAAs may have been independent for each. Taken together, these results offer preliminary evidence in support of a role for EAA treatment and increased protein consumption to offset muscle loss and functional mobility impairments following TKA.

The strengths of this study include a robust design with randomization, double blinding, and a placebo control; a reliance on previously validated procedures; rigorous measures showing a clear pattern of physiological and functional mobility results; the use of a relatively simple, safe, and widely disseminable intervention informed by prior research; and an equivalence of treatment conditions across a range of participant characteristics that encourages confidence in the generalization of results to older adults - especially older women - undergoing TKA. Limitations of the study include a relatively small $(n=28)$ sample from one surgical center, which restricted our ability to detect potential moderators or confounds (e.g., statin use). Despite randomization, differences in BMI may alter the response to surgery, rehabilitation, and EAA supplementation. In a larger sample, randomization may include a broader age range of patients, with exclusion based on baseline function rather than chronologic age.

In conclusion, we interpret these preliminary findings as supporting our hypothesis that 21 days of twice-daily ingestion of $20 \mathrm{~g}$ of EAAs attenuates muscle loss and helps to restore functional mobility. Bearing in mind the aforementioned limitations, these results may be considered a proof of principle that EAA supplementation in the preoperative and acute postoperative periods could improve patient outcomes. The present findings extend our understanding of the potential beneficial effects of EAA use in TKA patients between the ages of 60 and 80 years. In order to gauge the potential impact of EAA supplementation on muscle volume and functional mobility long term, future studies will need to follow patients for 6 months or 1 year. Also, future studies designed to identify the mechanisms of action, the durability of effect, and the safety and potential benefits of longer dosing regimes - and in a broader age range of patients, with followup questionnaires to assess the impact of treatment on quality of life - are needed so that the biomedical community can better equip the health care system to effectively treat the overwhelming number of older adults undergoing knee replacement surgery $(1,53-55)$.

\section{Methods}

Subjects. Twenty-eight subjects aged 60 to 80 years were recruited from a pool of surgical candidates from the Slocum Center for Orthopedics and Sports Medicine in Eugene, Oregon. All subjects were scheduled to undergo primary TKA. Exclusion criteria included untreated endocrine disease; significant heart, kidney, liver, blood, or respiratory disease; peripheral vascular disease; active cancer; and recent treatment with anabolic steroids or oral corticosteroids for greater than 1 week. After 


\section{Table 5}

MLM results associating change in muscle atrophy in TKA and nonoperated legs with change in functional mobility measures for all cases and split by group

\begin{tabular}{|c|c|c|c|c|c|c|}
\hline & \multicolumn{3}{|c|}{ TKA } & \multicolumn{3}{|c|}{ Nonoperated } \\
\hline & $\begin{array}{c}\text { Regression } \\
\text { coefficient }\end{array}$ & $F$ & $P$ & $\begin{array}{c}\text { Regression } \\
\text { coefficient }\end{array}$ & $F$ & $P$ \\
\hline & \multicolumn{6}{|c|}{ All cases } \\
\hline TUG & 1.57 & 5.78 & 0.021 & 0.58 & 1.35 & 0.52 \\
\hline 6-minute walk & 0.03 & 1.33 & 0.26 & 0.01 & 0.13 & 0.73 \\
\hline Stair-climb up & -0.5 & 0.61 & 0.44 & -0.89 & 3.35 & 0.08 \\
\hline Stair-climb down & 0.11 & 0.02 & 0.88 & 0.69 & 1.54 & 0.88 \\
\hline Protein intake ( $\mathrm{g} / \mathrm{kg}$ body mass) & 50.74 & 13.06 & 0.001 & 24.38 & 5.04 & 0.031 \\
\hline Time $^{A}$ & -1.24 & 42.24 & $<0.001$ & -0.85 & 24.28 & $<0.001$ \\
\hline \multicolumn{7}{|l|}{ Treatment group } \\
\hline Placebo & 0.22 & 0.002 & 0.97 & 0.57 & 0.03 & 0.87 \\
\hline EAA & REFB & & & REFB & & \\
\hline \multicolumn{7}{|l|}{ Time ${ }^{A}$ by treatment group } \\
\hline $\begin{array}{l}\text { Placebo by time } \\
\text { EAAs by time }\end{array}$ & $\begin{array}{l}-3.20 \\
\text { REFB }\end{array}$ & 12.59 & 0.001 & $\begin{array}{c}-1.64 \\
\text { REFB }\end{array}$ & 5.45 & 0.025 \\
\hline \multicolumn{7}{|l|}{ Placebo condition only } \\
\hline TUG & 0.74 & 0.59 & 0.46 & 0.22 & 0.06 & 0.82 \\
\hline 6-minute walk & 0.09 & 3.53 & 0.08 & 0.04 & 0.83 & 0.38 \\
\hline Stair-climb up & 0.57 & 0.31 & 0.59 & -0.10 & 0.01 & 0.92 \\
\hline Stair-climb down & -0.001 & 0.00 & 1.00 & 0.30 & 0.05 & 0.83 \\
\hline Protein intake ( $\mathrm{g} / \mathrm{kg}$ body mass) & 33.35 & 3.51 & 0.10 & 19.51 & 0.82 & 0.38 \\
\hline TimeA $^{A}$ & -4.44 & 35.79 & $<0.001$ & -2.48 & 11.51 & 0.005 \\
\hline \multicolumn{7}{|l|}{ EAA condition only } \\
\hline TUG & 2.30 & 6.02 & 0.025 & 0.87 & 2.22 & 0.15 \\
\hline 6-minute walk & -0.01 & 0.07 & 0.80 & -0.01 & 0.24 & 0.63 \\
\hline Stair-climb up & -1.70 & 3.06 & 0.097 & -1.43 & 5.64 & 0.028 \\
\hline Stair-climb down & 0.36 & 0.15 & 0.71 & 0.69 & 1.44 & 0.25 \\
\hline Protein intake ( $\mathrm{g} / \mathrm{kg}$ body mass) & 62.29 & 8.46 & 0.01 & 24.39 & 3.25 & 0.09 \\
\hline Time $^{A}$ & -1.10 & 3.32 & 0.087 & -0.80 & 4.46 & 0.05 \\
\hline
\end{tabular}

ATime, change from baseline to 2 weeks and 6 weeks after TKA in the analysis; ${ }^{\mathrm{B}} \mathrm{REF}$, referent for factorial comparisons.

signing the informed consent, each patient was randomly assigned to the placebo or EAA supplement group using random assignment procedures created for use by the research staff and the principal investigator. All researchers were blinded to the patients' assignment, and all patients were blinded to the treatment group.

Trial design. A two-arm, parallel trial design was used with a 1:1 allocation ratio to EAA versus placebo groups. All subjects completed MRI, strength, and functional testing 2 weeks prior to TKA (baseline), 2 weeks after TKA, and 6 weeks after TKA. Baseline measures of quadriceps volume (MRI), strength, and function were performed prior to surgery and before initiating supplementation. An MRI was performed before strength and functional testing at all time points. The study was conducted from May, 2010 to October, 2012. The trial was stopped due to a lack of sufficient funding.

Food diaries. The subjects were instructed to complete three 3-day food diaries on a specific Friday, Saturday, and Sunday during the study. Researchers explained the objectives and protocol during the first visit, and at each subsequent visit the subjects were interviewed about the data they recorded. The first 3-day food diary was completed before surgery. Postoperative food diaries were obtained 2 weeks and 6 weeks after TKA.

Supplementation. Placebo (nonessential amino acids) or EAA supplementation began 1 week before TKA, resumed again on postsurgical day 1 , and continued for 14 days, for a total of 21 days of supplementation.
Supplements were not ingested on the day of surgery. Ingestion of the supplement occurred twice daily, at $10 \mathrm{am}$ and again at $2 \mathrm{pm}$. During inpatient hospitalization, the morning supplement ingestion occurred 1 hour after physical therapy. The afternoon supplement ingestion occurred 1 hour after physical therapy. The goal of this supplementation regime was to maximize the anabolic effect of the EAAs (30). Supplement ingestion was recorded in a log book and verified by research personnel during regularly scheduled visits. Supplement composition for the EAAs was: histidine, $2.2 \mathrm{~g}$ (11\% of total); isoleucine, $2.0 \mathrm{~g}$ (10\%); leucine, $3.6 \mathrm{~g}$ (18\%); lysine, $3.2 \mathrm{~g}$ (16\%); methionine, $0.6 \mathrm{~g}$ (3\%); phenylalanine, $3.2 \mathrm{~g}$ (16\%); threonine, $2.8 \mathrm{~g}(14 \%)$; and valine, $2.4 \mathrm{~g}(12 \%)$. The placebo supplement consisted of $20 \mathrm{~g}(100 \%)$ alanine.

MRI acquisition and analysis. The details on muscle volume determination have been published previously, with slight modifications for the current trial (56). Two weeks before surgery, patients had an MRI of the bilateral lower extremities between the anterior superior iliac spine and the tibial plateau at the Slocum Center for Orthopedics and Sports Medicine MRI facility equipped with a Philips Achieva 8C 1.5T system. A T1-weighted, fast spin-echo pulse sequence using the following parameters obtained slice images of the mid-thigh region of interest: transmission times of $500 \mathrm{~ms}$ and an echo time of $12 \mathrm{~ms}$, and a field of view varied to match patient size, with 5 -mm slice thickness and a $256 \times 512$ acquisition matrix size. The pre-scan image was used by the operator to align post-scan parame- 
ters in order to determine changes in muscle tissue volume in the identical region of interest. Analysis consisted of matching five preoperative mid-thigh images to five identical postoperative ( 2 weeks and 6 weeks postoperation) mid-thigh images for quantification of muscle volume. Analysis was performed using the Analyze 11 software package (AnalyzeDirect, Inc.) with semiautomated delineation of quadriceps, hamstring, and adductor boarders. Using thresholding methods, the software can differentiate operator-delineated parameters set to distinguish muscle from nonmuscle (i.e., adipose tissue) using voxel intensity within each border region for quantitative determination of muscle volume. For each subject, a template of the quadriceps border was used to establish boundaries for successive images. One blinded researcher was responsible for analyzing all images. Intraclass correlation coefficients (ICCs) for the operator ranged from 0.96 to 0.99 . A second blinded researcher performed repeat analysis on nine randomly selected subjects' images from all three time points (baseline, 2 weeks after TKA, and 6 weeks after TKA). Betweentester ICCs ranged from 0.99 to 1.00 .

Medical Image Processing, Analysis and Visualization (MIPAV) software, version 7.0 (Center for Information Technology, NIH) (57) was used for the analysis of IMAT, which was defined as fat within and between muscle bundles beneath the deep facial border of the thigh. Images were first corrected for shading inhomogeneity with a nonparametric, nonuniform intensity normalization (N3) algorithm (58). Bone was eliminated, and a region of interest was manually defined at the level of the deep fascia for the same 5 slices analyzed for muscle volumes. Separation of contractile and noncontractile tissue was achieved by creating a voxel intensity histogram for each drawn region of interest and implementing the maximum entropy method available within MIPAV (59). Data were exported as volumes-per-voxel intensity and separated above (adipose tissue) and below (contractile tissue) the determined threshold value. Voxel intensities below 300 were separated and labeled as noncontractile tissue.

Strength. Strength and functional testing occurred at the Bowerman Sports Science Clinic of the University of Oregon. Isometric quadriceps strength was measured using a Biodex dynamometer (Biomedical Systems). Seat adjustments, shoulder and leg restraints, and transducer positioning were recorded for each subject for identical strength determination at each session. The medial and lateral epicondyles of the femur were used to position the subject's knee joint through the axis of rotation on the dynamometer. Strength was tested at three different degrees of flexion $(30,45$, and 60$)$. The subjects performed three 3 -second trials at each degree of flexion with 10 seconds' rest between trials for both flexion and extension. The trials were performed on both legs for a total of 18 trials (9 flexion, 9 extension).

Functional mobility. The measurements used to assess the subjects' functional mobility were the 6-minute walk, TUG, timed stair ascent, and timed stair descent tests. Each test was performed in the same order for all subjects at all three time points. First was the 6-minute walk. Patients were instructed to "walk as fast and as safely as you can" in a large indoor space within the testing facility. They were given time announcements at 3 minutes and at 5 minutes 40 seconds, with the last 10 seconds counted down aloud. The total distance walked in 6 minutes was recorded. Next was the TUG test. Each subject began the test in a seated position (all subjects were tested using the same chair), then stood up, walked forward 3 meters across a line that was clearly marked on the floor, then turned around, walked back 3 meters, and sat down in the same chair. The subjects were given verbal instructions to complete the task "as fast and as safely as you can," and the total time was recorded. The final test was the timed stair ascent and timed stair descent. Total time to go up and down the stairs and just the time to go down were measured. Timing started as soon as subjects made their initial movements forward or upward. The starting point for the descent portion was when subjects completely faced the stairs. The end point was when both of the subject's feet were at the starting spot on the ground in front of the staircase. All subjects were provided with verbal instructions to complete the test "as fast and as safely as you can." Subjects walked up and down a total of 8 steps. The same set of stairs was used for each testing session.

TKA. On the morning of surgery, subjects were admitted to Sacred Heart Medical Center at RiverBend (Springfield, Oregon, USA) in a fasting state. Either an epidural, spinal, or general anesthetic was administered. Approximately half of the subjects had a preoperative femoral nerve block placed for postoperative analgesia. The routine use of femoral nerve blocks was halted in January of 2012. Intravenous propofol was used to induce general anesthesia and was maintained with inhalational anesthetic (either desflurane or sevoflurane), with or without a muscle relaxant (rocuronium bromide). A 10-cm-wide Zimmer tourniquet was positioned around the proximal third of the thigh and inflated to 300 $\mathrm{mmHg}$ to ensure minimal blood flow to the operated leg. After completion of the main components of the surgery, the tourniquet was deflated, allowing for reperfusion of the limb with blood. The total tourniquet time was recorded for each subject. All subjects also had three muscle biopsies performed at baseline (prior to tourniquet inflation), during maximal ischemia, and during reperfusion from the vastus lateralis muscle of the operated leg (results not reported here) $(56,60,61)$.

Statistics. Analyses were performed using SPSS software, version 19.0 (SPSS Inc.). Statistical evaluation of our data was performed using separate analysis of covariance (ANOVA) models at 2 weeks and 6 weeks postoperation, comparing the EAA versus placebo groups in terms of percentage change from baseline on physiological and functional mobility measures. Models were adjusted for self-reported protein intake ( $\mathrm{g} / \mathrm{kg}$ body weight). Differences between the means were considered significant at $P \leq 0.05$. Differences between the means were considered a trend at $P \leq 0.10$. All values are expressed as the mean (SE) or a percentage.

Power calculations for these analyses were based on an expected effect size of $d=1.30$ for the main outcome measure of quadriceps mid-section volume, generated from preliminary data and prior studies. Assuming a 2-tailed type I error rate of 0.05 , a sample size of 24 ( 12 subjects per group) is sufficient to detect this anticipated effect with $85 \%$ power.

MLMs were specified to determine the extent to which muscle atrophy covaried with functional mobility variables and dietary protein over time. An MLM provides a strategy to estimate parameters accounting for correlations among nested responses, as occurs with repeated measures designs, and to maximize efficiency because it uses all available information for each respondent. Thus, the present multilevel analyses, which nested data from the three time points within each individual, properly partitioned the variance and accounted for the nonindependence of the data. Change in TKA and placebo quadriceps atrophy from baseline was modeled as a function of change in functional mobility variables (i.e., TUG, 6-minute walk, timed stair ascent, timed stair descent) and protein intake, using approaches that completely partition between- and withinsubject effects $(62,63)$. The models were constructed as the amount of change relative to baseline on the mid-quadriceps atrophy outcome variables (i.e., outcome values were calculated as 0 at baseline, 2 -week value minus baseline value at 2 weeks, and 6 -week value minus baseline value at 6 weeks) and as individuals' deviations from their personal mean values on the predictors. Individual mean values of the outcome and predictors were included as fixed covariates.

Study approval. This study was approved by the PeaceHealth Institutional Review Board, Sacred Heart Medical Center at RiverBend, and the Biomedical Institutional Review Board of the University of Oregon, and 
was conducted in accordance with the Declaration of Helsinki. All subjects provided written informed consent prior to their participation in the study. This study was registered at www.clinicaltrials.gov (NCT00760383).

\section{Acknowledgments}

We thank the TKA patients who participated in this study for their time, effort, and patience. We also thank Crystal Mills, Alicia Morrison, Brian Pifer, and Sam Hannah of the Slocum Center for Orthopedics and Sports Medicine for their help with patient recruitment and scheduling of patient MRIs. We are grateful to Joni Strub, OR Nurse Manager, and the nurses and physical ther- apists at Sacred Heart Medical Center at RiverBend, as well as to the anesthesiologists from the Northwest Anesthesia Physicians group for their assistance with the study.

Received for publication March 27, 2013, and accepted in revised form September 3, 2013.

Address correspondence to: Hans C. Dreyer, University of Oregon, Department of Human Physiology, 1240 University of Oregon, Eugene, Oregon 97403-1240, USA. Phone: 541.346.5775; Fax: 541.346.2841; E-mail: hcdreyer@uoregon.edu.
1. Kurtz S, Ong K, Lau E, Mowat F, Halpern M. Projections of primary and revision hip and knee arthroplasty in the United States from 2005 to 2030. J Bone Joint Surg. 2007;89(4):780-785

2. Lorentzen JS, Petersen MM, Brot C, Madsen OR. Early changes in muscle strength after total knee arthroplasty. A 6-month follow-up of 30 knees. Acta Orthop Scand. 1999;70(2):176-179.

3. Mizner RL, Snyder-Mackler L. Altered loading during walking and sit-to-stand is affected by quadriceps weakness after total knee arthroplasty. J Orthop Res. 2005;23(5):1083-1090.

4. Stevens JE, Mizner RL, Snyder-Mackler L. Quadriceps strength and volitional activation before and after total knee arthroplasty for osteoarthritis. J Orthop Res. 2003;21(5):775-779.

5. Moxley Scarborough D, Krebs DE, Harris BA. Quadriceps muscle strength and dynamic stability in elderly persons. Gait Posture. 1999;10(1):10-20.

6. Brown M, Sinacore DR, Host HH. The relationship of strength to function in the older adult. J Gerontol A Biol Sci Med Sci. 1995;50(spec no):55-59.

7. Mizner RL, Petterson SC, Snyder-Mackler L. Quadriceps strength and the time course of functional recovery after total knee arthroplasty. J Orthop Sports Phys Ther. 2005;35(7):424-436.

8. Moreland JD, Richardson JA, Goldsmith CH, Clase CM. Muscle weakness and falls in older adults: a systematic review and meta-analysis. J Am Geriatr Soc. 2004;52(7):1121-1129.

9. Finch E, Walsh M, Thomas SG, Woodhouse LJ. Functional ability perceived by individuals following total knee arthroplasty compared to agematched individuals without knee disability. J Orthop Sports Phys. 1998;27(4):255-263.

10. Wylde V, Dieppe P, Hewlett S, Learmonth ID. Total knee replacement: is it really an effective procedure for all? Knee. 2007;14(6):417-423.

11. Noble PC, Gordon MJ, Weiss JM, Reddix RN, Conditt MA, Mathis KB. Does total knee replacement restore normal knee function? Clin Orthop Relat. 2005;(431):157-165.

12. Kennedy DM, Stratford PW, Hanna SE, Wessel J, Gollish JD. Modeling early recovery of physical function following hip and knee arthroplasty. $B M C$ Musculoskelet Disord. 2006;7:100.

13. Zeni JA, Snyder-Mackler L. Early postoperative measures predict 1 - and 2-year outcomes after unilateral total knee arthroplasty: importance of contralateral limb strength. Phys Ther. 2010; 90(1):43-54.

14. Meier WA, et al. The long-term contribution of muscle activation and muscle size to quadriceps weakness following total knee arthroplasty. J Geriatr Phys Ther. 2009;32(2):35-38.

15. Meier W, Mizner RL, Marcus RL, Dibble LE, Peters C, Lastayo PC. Total knee arthroplasty: muscle impairments, functional limitations, and recommended rehabilitation approaches. J Orthop Sports Phys Ther. 2008;38(5):246-256.

16. Petterson SC, et al. Improved function from progressive strengthening interventions after total knee arthroplasty: a randomized clinical trial with an imbedded prospective cohort. Arthritis Rheum. 2009;61(2):174-183.

17. Yoshida Y, Mizner RL, Ramsey DK, Snyder-Mackler L. Examining outcomes from total knee arthroplasty and the relationship between quadriceps strength and knee function over time. Clin Biomech (Bristol, Avon). 2008;23(3):320-328.

18. Miner AL, Lingard EA, Wright EA, Sledge CB, Katz JN. Knee range of motion after total knee arthroplasty: how important is this as an outcome measure? J Arthroplasty. 2003;18(3):286-294.

19. Cesari M, et al. Biomarkers of sarcopenia in clinical trials-recommendations from the International Working Group on Sarcopenia. J Cachexia Sarcopenia Muscle. 2012;3(3):181-190.

20. Fielding RA, et al. Sarcopenia: an undiagnosed condition in older adults. Current consensus definition: prevalence, etiology, and consequences. International working group on sarcopenia. $J \mathrm{Am}$ Med Dir Assoc. 2011;12(4):249-256.

21. Janssen I, Heymsfield SB, Ross R. Low relative skeletal muscle mass (sarcopenia) in older persons is associated with functional impairment and physical disability. J Am Geriatr Soc. 2002;50(5):889-896.

22. Branch LG, et al. A prospective study of incident comprehensive medical home care use among the elderly. Am J Public Health. 1988;78(3):255-259.

23. Wolinsky FD, Callahan CM, Fitzgerald JF, Johnson RJ. The risk of nursing home placement and subsequent death among older adults. J Gerontol. 1992;47(4):S173-S182.

24. Ferrucci L, Guralnik JM, Pahor M, Corti MC, Havlik RJ. Hospital diagnoses, Medicare charges, and nursing home admissions in the year when older persons become severely disabled. JAMA. 1997;277(9):728-734.

25. Janssen I, Shepard DS, Katzmarzyk PT, Roubenoff $\mathrm{R}$. The healthcare costs of sarcopenia in the United States. J Am Geriatr Soc. 2004;52(1):80-85.

26. Dreyer HC, Volpi E. Role of protein and amino acids in the pathophysiology and treatment of sarcopenia. J. 2005;24(2):140S-145S.

27. Dillon EL, et al. Amino acid supplementation increases lean body mass, basal muscle protein synthesis, and insulin-like growth factor-I expression in older women. J Clin Endocrinol Metab. 2009;94(5):1630-1637.

28. Leenders M, et al. Prolonged leucine supplementation does not augment muscle mass or affect glycemic control in elderly type 2 diabetic men. J Nutr. 2011;141:1070-1076.

29. Verhoeven S, et al. Long-term leucine supplementation does not increase muscle mass or strength in healthy elderly men. Am J Clin Nutr. 2009; 89:1468-1475.

30. Dreyer HC, et al. Leucine-enriched essential amino acid and carbohydrate ingestion following resistance exercise enhances mTOR signaling and protein synthesis in human muscle. Am J Physiol Endocrinol. 2008;294(2):E392-E400.

31. Fujita S, Dreyer HC, Drummond MJ, Glynn EL, Volpi E, Rasmussen BB. Essential amino acid and carbohydrate ingestion before resistance exercise does not enhance postexercise muscle protein synthesis. J Appl Physiol. 2009;106(5):1730-1739.

32. Jordan LY, Melanson EL, Melby CL, Hickey MS, Miller BF. Nitrogen balance in older individuals in energy balance depends on timing of protein intake. J Gerontol A Biol Sci Med Sci. 2010;65(10):1068-1076.

33. Breen L, et al. Two weeks of reduced activity decreases leg lean mass and induces "anabolic resistance" of myofibrillar protein synthesis in healthy elderly. J Clin Endocrinol Metab. 2013;98(6):2604-2612.

34. Lawson RM, Doshi MK, Barton JR, Cobden I. The effect of unselected post-operative nutritional supplementation on nutritional status and clinical outcome of orthopaedic patients. Clin Nutr. 2003;22(1):39-46.

35. Lawson RM, Doshi MK, Ingoe LE, Colligan JM, Barton JR, Cobden I. Compliance of orthopaedic patients with postoperative oral nutritional supplementation. Clin Nutr. 2000;19(3):171-175.

36. Parker BA, et al. Effect of statins on skeletal muscle function. Circulation. 2013;127(1):96-103.

37. Mikus CR, et al. Simvastatin impairs exercise training adaptations. J Am Coll Cardiol. 2013;62(8):709-714.

38. Phillips SM, Glover EI, Rennie MJ. Alterations of protein turnover underlying disuse atrophy in human skeletal muscle. J Appl Physiol. 2009;107(3):645-654.

39. Rennie MJ, et al. Facts, noise and wishful thinking: muscle protein turnover in aging and human disuse atrophy. Scand J Med Sci Sports. 2010;20(1):5-9.

40. Combaret L, et al. A leucine-supplemented diet restores the defective postprandial inhibition of proteasome-dependent proteolysis in aged rat skeletal muscle. J Physiol. 2005;569(pt 2):489-499.

41. Katsanos CS, Kobayashi H, Sheffield-Moore M, Aarsland A, Wolfe RR. A high proportion of leucine is required for optimal stimulation of the rate of muscle protein synthesis by essential amino acids in the elderly. Am J Physiol Endocrinol. 2006;291(2):E381-E387.

42. Guillet C, et al. Whole body protein breakdown is less inhibited by insulin, but still responsive to amino acid, in nondiabetic elderly subjects. J Clin Endocrinol Metab. 2004;89(12):6017-6024.

43. Matthews DE. Observations of branched-chain amino acid administration in humans. J Nutr. 2005;135(6 suppl):1580S-1584S.

44. Mizner RL, Petterson SC, Stevens JE, Vandenborne K, Snyder-Mackler L. Early quadriceps strength loss after total knee arthroplasty. The contributions of muscle atrophy and failure of voluntary muscle activation. J Bone Joint Surg. 2005;87(5):1047-1053.

45. Thomas AC, Stevens-Lapsley JE. Importance of attenuating quadriceps activation deficits after total knee arthroplasty. Exerc Sport Sci Rev. 2012;40(2):95-101.

46. Yoshida Y, Marcus RL, Lastayo PC. Intramuscular adipose tissue and central activation in older adults. Muscle Nerve. 2012;46(5):813-816.

47. Goodpaster BH, et al. Attenuation of skeletal muscle and strength in the elderly: The Health $\mathrm{ABC}$ Study. J Appl Physiol. 2001;90(6):2157-2165.

48. Goodpaster BH, Kelley DE, Thaete FL, He J, Ross 
R. Skeletal muscle attenuation determined by computed tomography is associated with skeletal muscle lipid content. J Appl Physiol. 2000;89(1):104-110.

49. Manini TM, Clark BC, Nalls MA, Goodpaster BH, Ploutz-Snyder LL, Harris TB. Reduced physical activity increases intermuscular adipose tissue in healthy young adults. Am J Clin Nutr. 2007;85(2):377-384.

50. Marcus RL, Addison O, LaStayo PC. Intramuscular adipose tissue attenuates gains in muscle quality in older adults at high risk for falling. A brief report. J Nutr Health Aging. 2013;17(3):215-218.

51. Goodpaster BH, et al. The loss of skeletal muscle strength, mass, and quality in older adults: the health, aging and body composition study. J Gerontol A Biol Sci Med Sci. 2006;61(10):1059-1064.

52. Frontera WR, Hughes VA, Fielding RA, Fiatarone MA, Evans WJ, Roubenoff R. Aging of skeletal muscle: a 12-yr longitudinal study. J Appl Physiol. 2000;88(4):1321-1326

53. Kurtz SM, et al. International survey of primary and revision total knee replacement. Int Orthop. 2011;35(12):1783-1789.

54. Kurtz S, Mowat F, Ong K, Chan N, Lau E, Halpern M. Prevalence of primary and revision total hip and knee arthroplasty in the United States from 1990 through 2002. J Bone Joint Surg. 2005;87(7):1487-1497.

55. Ong KL, Mowat FS, Chan N, Lau E, Halpern MT, Kurtz SM. Economic burden of revision hip and knee arthroplasty in Medicare enrollees. Clin Orthop Relat Res. 2006;446:22-28.

56. Ratchford SM, et al. Proteins regulating cap-dependent translation are downregulated during total knee arthroplasty. Am J Physiol Regul Integr Comp Physiol. 2012;302(6):R702-R711.

57. McAuliffe M, Lalonde F, McGarry D, Gandler W, Csaky K, Trus B. Medical image processing, analysis \& visualization in clinical research. IEEE Com puter Based Medical Sciences (CBMS). 2001:381-386.

58. Sled JG, Zijdenbos AP, Evans AC. A nonparametric method for automatic correction of intensity nonuniformity in MRI data. IEEE Trans Med Imaging.
1998;17(1):87-97.

59. Akima H, et al. Relationships of thigh muscle contractile and non-contractile tissue with function, strength, and age in boys with Duchenne muscular dystrophy. Neuromuscul Disord. 2012;22(1):16-25.

60. Bailey AN, et al. MAFbx, MuRF1, and the stress-activated protein kinases are upregulated in muscle cells during total knee arthroplasty. Am J Physiol Regul Integr Comp Physiol. 2012;303(4):R376-R386.

61. Hocker AD, Boileau RM, Lantz BA, Jewett BA, Gilbert JS, Dreyer HC. Endoplasmic reticulum stress activation during total knee arthroplasty [published online ahead of print August 22, 2013]. Physiol Rep. doi:10.1002/phy2.52.

62. Neuhaus JM, Kalbfleisch JD. Between- and withincluster covariate effects in the analysis of clustered data. Biometrics. 1998;54(2):638-645.

63. Hedeker D, Gibbons R. Mixed-effects regression models for continuous outcomes. In: Longitudinal Data Analyses. Hoboken, New Jersey, USA: Wiley and Sons. 2006:155-161. 